\title{
Development of methane decarbonisation based on liquid metal technology for $\mathrm{CO}_{2}$-free production of hydrogen
}

\author{
Alberto Abánades ${ }^{\text {a,c, }}$, Renu Kumar Rathnam ${ }^{\text {a }}$, Tobias Geißler ${ }^{\text {b }}$,Annette Heinzel ${ }^{\text {, }}$, Kian \\ Mehravaran ${ }^{\mathrm{a}}$, George Müller ${ }^{\mathrm{b}}$, Michael Plevan $^{\mathrm{b}}{ }$, Carlo Rubbia ${ }^{\mathrm{a}}$, Delia Salmieri ${ }^{\mathrm{a}}$, Leonid Stoppel \\ ${ }^{\mathrm{b}}$, Stefan Stückrad ${ }^{\mathrm{a}}$, Alfons Weisenburger ${ }^{\mathrm{b}}$, Horst Wenninger ${ }^{\mathrm{a}}$, Thomas Wetzel $^{\mathrm{b}}$

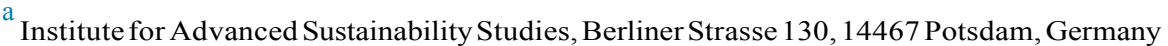 \\ ${ }^{b}$ Karlsruhe Institute of Technology, Hermann-von-Helmholtz-Platz 1, 76344 Eggenstein-Leopoldshafen, Germany \\ ${ }^{\mathrm{c}}$ Universidad Politecnica de Madrid, c/Jose Gutierrez Abascal 2, 28006 Madrid, Spain \\ Corresponding author. Universidad Polit_ecnica de Madrid, c/Jos_e Guti_errez Abascal 2, 28006 Madrid, Spain. \\ Tel.: +34 913364268; fax: +34 913363079. E-mail addresses: abanades@etsii.upm.es, alberto.abanades@iass-potsdam.de (A. Abánades)
}

Keywords: methane decarbonisation; technology development; liquid metal; hydrogen; carbon

\section{Abstract}

The development of a low-carbon technique to produce hydrogen from fossils would be of great importance during the transition to a long-term sustainable energy system. Methane decarbonisation, the well-known transformation of methane into hydrogen and solid carbon, is a potential candidate in this regard. At the Institute for Advanced Sustainability Studies (IASS), a new alternative technology for methane decarbonisation applying liquid metal technology was proposed and an ambitious programme was set up in collaboration with the Karlsruhe Institute of Technology (KIT). The comprehensive programme included the following: conceptual design of a liquid metal bubble column reactor and material testing, process engineering incorporating carbon separation and hydrogen purification, and a socio-economic analysis. In the present paper, an overview of the programme along with some of the results, are presented. Results from the experimental campaigns show that the liquid metal reactor design works effectively in producing hydrogen and carbon separation. Other aspects of the technology such as socio-economics, environmental impact, and scalability also seem to be favourable making methane decarbonisation based on liquid metal technology a potential candidate for $\mathrm{CO}_{2}$-free hydrogen production.

\section{Introduction}

Energy is one of the basic needs of our society and a sustainable energy system is a must for the long term stability and development of humankind. This means that the energy demand should be met from technologies that are sustainable from an environmental, economic, and social point of view. A sustainable energy system should be based on renewable or long term available resources and should not cause major irreversible changes in our ecosystem.

To progress towards a sustainable society, the implementation of a low-carbon energy system is crucial and should be one of the pillars of the energy and environmental policies around the world. However, this aim should be compatible with the economic and social aspects as well. Hydrogen is one of the energy vectors that could play a role in the implementation, as it can be produced from most of the available energy sources. As pointed out by many authors before, a low-carbon energy system will likely be based on carbon-free renewable or nuclear energy sources. Nevertheless, the transition phase will require the $\mathrm{CO}_{2}$-free utilisation of fossil fuels, in particular natural gas, most likely for decades from now, and this calls for innovative 
solutions. This issue also affects the current hydrogen production processes, such as steam reforming and gasification that generate $\mathrm{CO}_{2}$ emissions. The development of a low-carbon technology to produce hydrogen from fossil-fuels would be of great importance during the transition to a long-term sustainable energy system [1]. The potential options are applying Carbon Capture and Sequestration (CCS) or Usage (CCU) to existing reforming and gasification processes, or developing alternative fossil-fuel decarbonisation pathways. However, the CCS technologies entail critical technical, economic, and safety-related challenges that are far from being resolved. There are also public acceptance and environmental concerns arising from CCS, ranging from the need to ensure suitable long-lasting storage to finding efficient, environmentally friendly $\mathrm{CO}_{2}$ capture technologies.

The decarbonisation of fossil fuels, especially, natural gas, is an attractive alternative and offers certain advantages over the use of CCS technologies [2]. Methane decarbonisation by pyrolysis ('methane cracking') involves the splitting of methane $\left(\mathrm{CH}_{4}\right)$ into its molecular components: solid carbon $(\mathrm{C})$ and hydrogen $\left(\mathrm{H}_{2}\right)$. Its main advantage lies in the lack of $\mathrm{CO} / \mathrm{CO}_{2}$ emissions, and in fact, in contrast to $\mathrm{CCS}$ and $\mathrm{CCU}$, it replaces the management of $\mathrm{CO}_{2}$ with a much lower amount of easier-to-handle solid carbon. Hydrogen represents an important clean energy carrier, with an already sizeable demand and promising prospects for the future energy system; it is also an important industrial commodity. Additionally, carbon is potentially marketable as a product for both current and envisaged usages (carbon fibres, materials, nanotechnology, etc.). On the other hand, the development of methane decarbonisation concepts has suffered drawbacks and an industrial process has not been deployed until now [3]. In this paper, we describe an approach to evaluate at laboratory scale a novel methane decarbonisation process that is capable of overcoming the obstacles and could lead to its industrial implementation. An overview of natural gas utilisation options in the light of $\mathrm{CO}_{2}$ emissions is shown in Fig. 1.

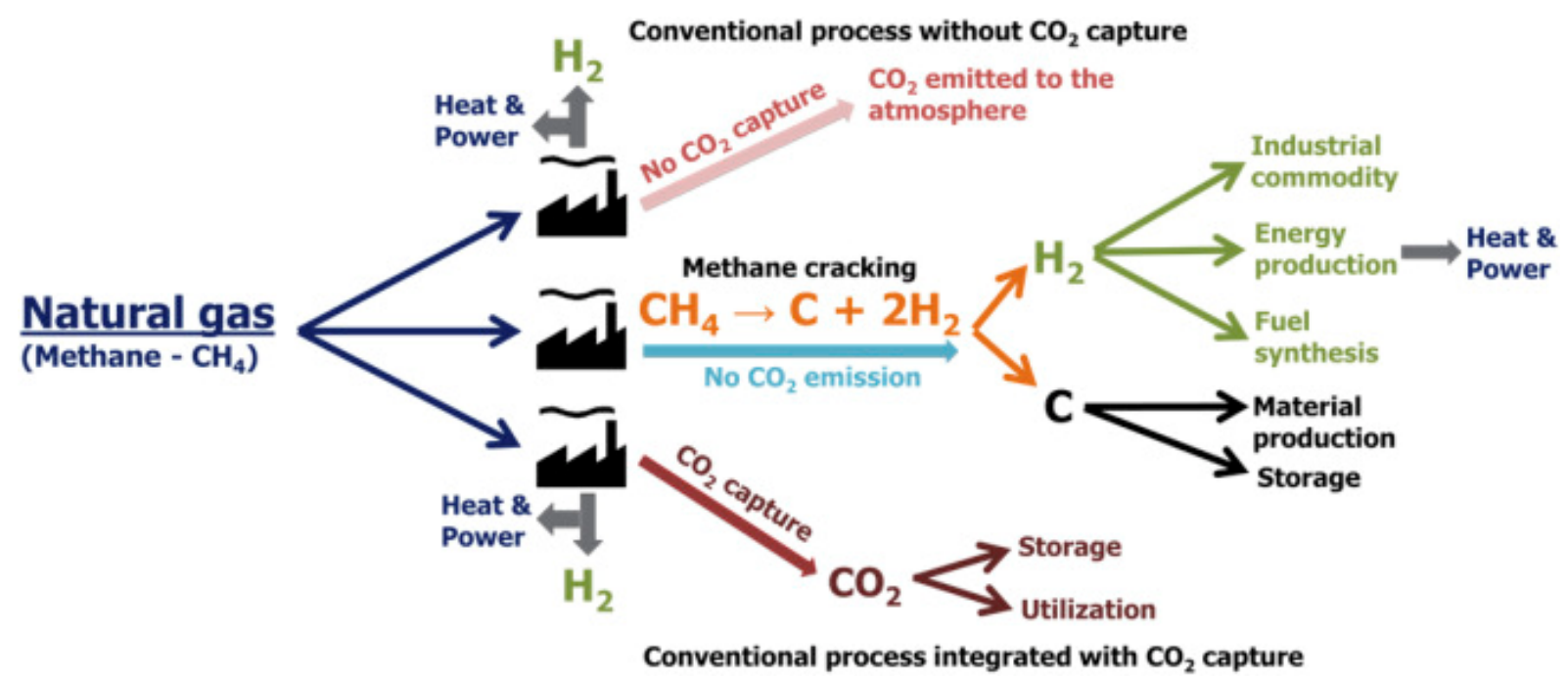

Fig. 1 - Overview of natural gas utilisation options in the light of $\mathrm{CO}_{2}$ emissions.

\section{Methane decarbonisation}

Methane is a rather stable molecule that has been widely studied due to its abundance and its extensive application as raw material for many industrial processes and its importance as an energy source. Apart of its direct combustion application, its high hydrogen to carbon ratio has converted methane into one of the main raw materials for hydrogen production integrated in important sectors such as ammonia production or fuel hydrogenation. The thermal dissociation 
of methane has been extensively studied from the 60s until now. Methane pyrolysis is an endothermic process $\mathrm{CH} 4 \rightarrow \mathrm{C}+2 \mathrm{H} 2(\Delta \mathrm{h} 0=74.85 \mathrm{~kJ} / \mathrm{mol})(1)$ that requires high temperatures of the order of $1000{ }^{\circ} \mathrm{C}$ to obtain significant conversion of methane. Methane is known to be unstable with respect to its elements $\left(\mathrm{C} \& \mathrm{H}_{2}\right)$ from $527^{\circ} \mathrm{C}$. However, it is the most stable hydrocarbon up until $1027^{\circ} \mathrm{C}[4]$.

$$
\mathrm{CH}_{4} \rightarrow \mathrm{C}+2 \mathrm{H}_{2} \quad\left(\Delta \mathrm{h}_{0}=74.85 \frac{\mathrm{kJ}}{\mathrm{mol}}\right)
$$

The reaction is initiated with the formation of a free radical $\mathrm{CH}_{4} \rightarrow \mathrm{CH}_{3} *+\mathrm{H}^{*}$ that dominates the kinetics of the reaction splitting the $\mathrm{C}-\mathrm{H}$ bond (dissociation energy: $434.72 \mathrm{~kJ} / \mathrm{mol}$ ), which requires high temperature levels [5]. Our evaluation of the reaction thermodynamic equilibrium mole fraction with Cantera library [6] is depicted in Fig. 2. It could be seen that above $1273 \mathrm{~K}$ $\left(1000^{\circ} \mathrm{C}\right)$, almost complete conversion of methane into hydrogen is theoretically feasible.

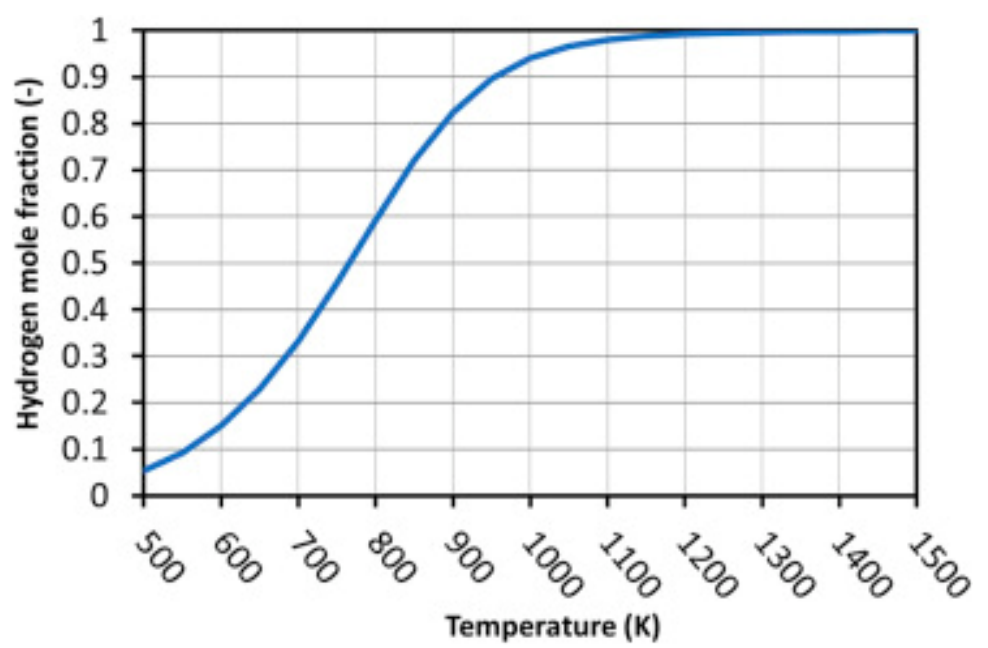

Fig. 2 - Hydrogen mole fractions (in the gas phase excluding solid carbon) attained during thermodynamic equilibrium of the methane cracking reaction at various temperatures and 1 bar pressure.

Significant effort has been previously dedicated to provide catalysts to the reaction in order to achieve a viable implementation below $1000{ }^{\circ} \mathrm{C}$. In particular, metallic catalysts based on $\mathrm{Ni}$ and $\mathrm{Fe}$ have achieved quite interesting conversion rates at temperatures of the order of $600-700{ }^{\circ} \mathrm{C}$ [7]. Carbon-based catalysts such as black carbon or activated carbon have been also proposed [8]. Fig. 3 gives a schematic view of the application range of the main catalyst types.

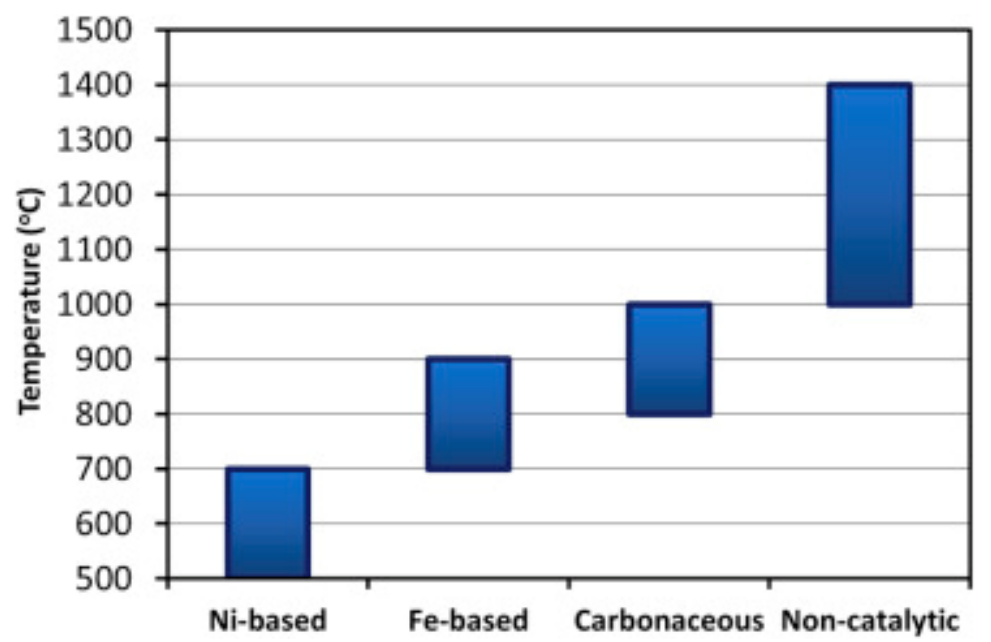

Fig. 3 - Catalyst types used for methane cracking and their temperature range of applicability. 
The practical industrial implementation in the case of catalysed reactions is limited by the deactivation of the catalyst and its cost. The deactivation of the catalyst is a process resulting from the formation of coke on the surface of the catalyst during its operation and its control is a very important challenge. In the case of carbonaceous catalysts, carbon from the pyrolysis process reduces the active surface, and finally eliminating its catalytic effect [9]. A detailed review on the thermocatalytic decomposition of methane has been recently published by Ashik et al. [10]. The review has discussed in detail the effect of catalysts on the process of thermal decomposition of methane. Catalyst regeneration and co-feeding of methane with other hydrocarbons were proposed as solutions to the issue of catalyst deactivation.

In spite of these problems, methane decarbonisation was implemented in the HYPRO project by Universal Oil Products in the 1960s, based on a fluidized bed reactor with Ni-Fe-Co catalyst in $\mathrm{Al}_{2} \mathrm{O}_{3}$ support $[11]$. The system with two fluidized bed was too complex and expensive and hence not viable.

Another major challenge is the regeneration of the spent catalyst that is mainly done with air or steam. Air regeneration is able to produce energy that will cover part of the energy demand for the methane cracking process, but has as main drawbacks: catalyst oxidation, production of hot spots, sintering and disintegration of the catalyst leading to its destruction [12]. Steam regeneration is more promising from the point of view of the catalyst integrity, as many regeneration cycles have been reported for Ni-based catalysts, although small amounts of filamentous carbon remained, reducing the catalyst performance slightly [13].

One more major issue associated with the current technological proposals can arise from the scale-up of the process. The step forward from the experimental device, based generally on a tubular reactor in the case of direct methane cracking, to an industrial scale system is not trivial. An industrial system might not be a result of a simple multiplication of tubes to reach a reasonable amount of hydrogen production, for instance, a few MW. The economic viability of the system may require the design of reactors with higher volumes that need to be heated by an external source to reach the operating temperature. A device based on a gaseous volume is limited by the thermo-physical properties of the gas itself if it is required to maintain a stable high temperature. Thermal conductivity, for instance, and thermal diffusivity will limit the volume of a temperature controlled process in which an endothermic reaction is taking place. The utilization of carbon particles for a better thermal homogeneity is a potential good option to overcome this problem.

From the analysis of previous work on the topic, it could be realized that the technological development of methane decarbonisation has apparently been slowed down by some technical difficulties. The main technical issues are the production of carbon and the subsequent reactor clogging and catalyst deactivation. In Fig. 4, carbon agglomeration inside the reactor from carbon seeds attached to the reactor wall is shown [14]. 


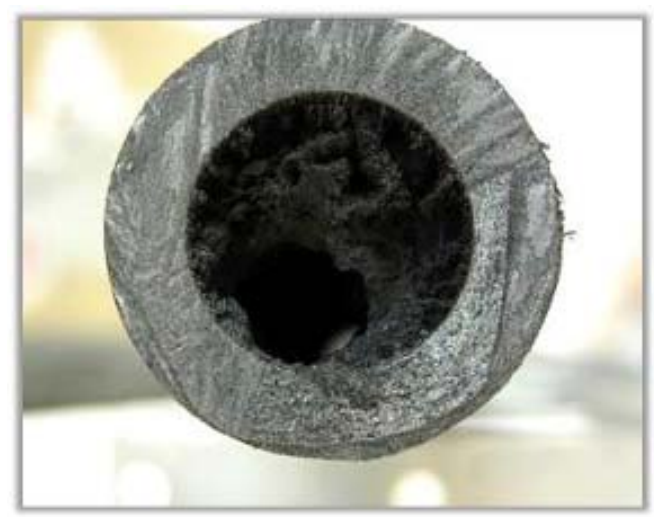

Fig. 4 - Carbon clogging in a tubular experimental reactor $[14]$

\section{Application of liquid metal technology to methane decarbonisation}

In 1930, Tyrer [15] had proposed and patented a process for producing hydrogen from methane or methane containing gases using molten iron (1200-1300 $\left.{ }^{\circ} \mathrm{C}\right)$. More recently, Steinberg [16] has also a proposed a methane decomposition process using liquid metal technology for producing hydrogen from natural gas; molten tin was recommended for the process. The proposed process for hydrogen production was part of an overall process for producing methanol by combining the produced hydrogen later with $\mathrm{CO}_{2}$. Serban et al. [17] proposed a process for utilising the heat generated in Generation IV nuclear reactors for direct contact pyrolysis of natural gas to produce hydrogen and carbon without any greenhouse gas emissions. The reproducibility of the results from their experimental work in the presence of tin and lead and very low flow rates (less than $10 \mathrm{ml} / \mathrm{min}$ ) needs to be confirmed [17]. Martynov et al. [18] proposed a methane pyrolysis process for hydrogen production by direct-contact heat transfer from heavy liquid metal coolants $(\mathrm{Pb}-\mathrm{Bi})$. Paxman et al. ${ }^{[19]}$ have presented their preliminary experimental and theoretical investigations on methane cracking for hydrogen production with a molten metal reactor. Their ultimate goal is to build and test a prototype solar reactor with molten metal for methane cracking.

A process for producing hydrogen from methane using liquid metal (tin) and methane flowing through a capillary reactor in slug flow has been proposed and studied by researchers at the Technical University of Dortmund [20]. Their initial experiments at $1100{ }^{\circ} \mathrm{C}$ revealed that an average methane conversion of $32 \%$ was possible without carbon depositions. The continuous thin liquid metal film that is formed on the capillary reactor wall avoids carbon deposition and also the reverse reactions. The capillary reactor was operated continuously for over $5 \mathrm{~h}$ and found no carbon deposits in the reaction zone after draining the liquid tin. The authors claim that the residence times in the reactor could be varied by changing the gas and liquid flows independently or in unison according to the requirements. This feature offers a significant advantage over liquid metal bubble column reactors. They concluded that residence times higher than $10 \mathrm{~s}$ and reaction temperatures lower than $1200^{\circ} \mathrm{C}$ could be achieved without any difficulty in the capillary molten metal reactor resulting in high methane conversions.

The preferred option, in most of the previous studies, for liquid media is based on molten metals, as carbon separation seems more achievable during the process due to the density difference between the liquid metal and the carbon. In our point of view, the use of molten media to host the methane cracking reactions is promising, although preliminary experimental work is necessary to confirm if a continuous operation scheme may be feasible at industrial scale. A reasonable range for the reaction temperature for a methane cracking process applying liquid media should be determined as well. The main source of problems might be the compatibility 
between hydrogen, carbon and the molten media and their thermal stability should be evaluated at the reaction conditions, as well as the kinetics and rates versus temperature of the reaction. The application of molten media should avoid the problems associated with reactor clogging due to carbon agglomeration, but opens new questions related to corrosion, especially when steel-based materials are used. Nevertheless, carbon separation processes from the liquid media should be developed from additional experimental evaluation.

In this direction, we have initiated a research project in which we try to shed some light about the feasibility of using liquid metal reactors to develop a technology for methane decarbonisation. This paper provides an overview of the project and its current status.

\section{Project development overview}

A collaborative R\&D project between the Institute for Advanced Sustainability Studies (IASS) and the Karlsruhe Institute of Technology (KIT) was initiated to design and develop a reactor based on liquid metal technology in order to overcome the technological uncertainties associated with the industrial implementation of methane cracking. The outcome of the project will be three fold:

- The evaluation of the technical feasibility of a liquid metal bubble column reactor concept for methane decarbonisation.

- The proposal of the reference process engineering for a methane decarbonisation facility.

- Realization of the socio-economic analysis of the technology.

The 30-month project with a fast track approach to develop an industrial methane cracking process commenced in December 2012. Fig. 5 shows the relationship between different tasks of the project.

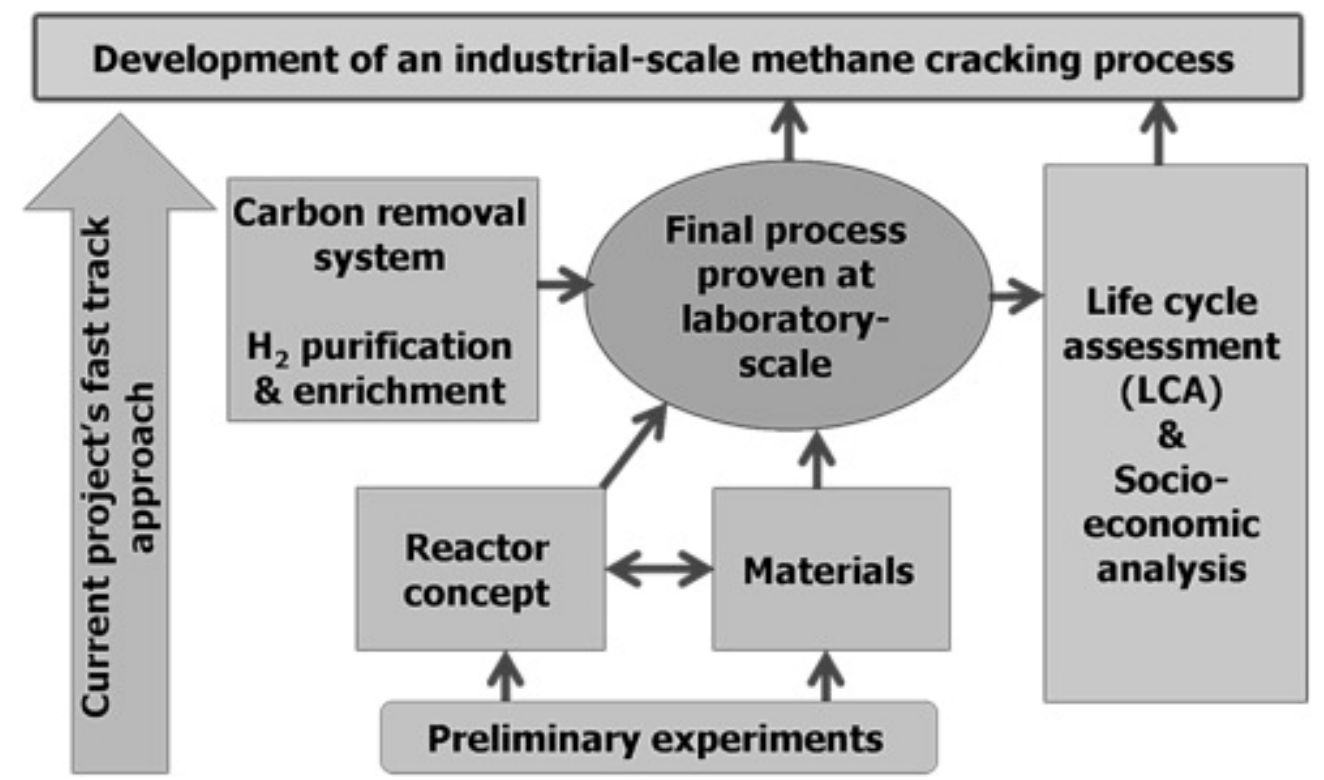

Fig. 5 - Main tasks of the project to develop a process for methane decarbonisation based on liquid metal technology.

Our first task was the realization of a conceptual design of a bubble column reactor for preliminary methane cracking experiments [21]. In parallel to the reactor concept, material 
testing was also carried out to confirm the material choice for the reactor. The improvements and feedbacks from the reactor experiments and material compatibility tests will produce a final reactor configuration. The requirements for additional equipment for auxiliary tasks such as carbon removal and hydrogen/hydrocarbon purification will be established and a process will be proposed.

As a support to the technological development, a socio-economic analysis which also includes a life cycle assessment is being performed to evaluate the benefits and the chance of success of the technology in the current socio-economic context and in relation to potential competitors, existing and alternative technologies for hydrogen production, such as steam reforming and electrolysis with wind energy.

\section{Technical feasibility}

The basic operational parameters, such as, reaction temperature and inlet methane flow rate, significantly influence the conversion of methane to hydrogen, and hence the hydrogen production rate. A dedicated experimental facility is currently in place to investigate the performance of the methane cracking reaction in a liquid metal bubble column reactor and study the evolution of the reaction rates versus temperature and to test additional technological features as well. Previous effort has also been made to evaluate the need of a catalyst for the reaction.

The design of the experimental reactor should serve to check the absence of critical technological show-stoppers in the scale-up of the system to an industrial device and the possibility of operating the reactor continuously without any issues, and be able to answer some questions related to the type of carbon that is produced. A tubular reactor design with a methane bubble injection mechanism has been proposed. Information on the carbon formed and its location obtained from the experiments would shed some light on the options for its removal from the reactor.

The technical feasibility of a methane cracking reactor based on liquid metal technology is dependent on material compatibility as well. In that sense, suitable materials should be selected for its long-term structural integrity with liquid metals, such as, tin or lead, at the operating temperatures (likely up to $1200^{\circ} \mathrm{C}$ ) in the presence of hydrogen. This analysis includes corrosion, erosion, and chemical attack that can lead to the formation of carbides and hydrides, as well as alloys or compounds derived from the corrosion products.

\section{Process engineering}

The engineering of a methane decarbonisation process is one of the objectives of the project. The process engineering integrates all the information obtained from the experimental verification to propose a reliable scheme for the industrial implementation of the technology. The steps in the development of the process are the following:

- Determination of the basic functional units required for the process in view of the experimental results. Possible units include: carbon and hydrogen separation, gas stream filtering, methane conditioning or any other ancillary units.

- Evaluation of the technological options for the functional units.

- Integration of the technological options to form the process scheme.

- Evaluation of the mass and energy balances. 
The preliminary process engineering will produce important data that could be used to evaluate the technical and economic feasibilities of the technology.

\section{Socio-economic analysis}

Potential benefits to society and people welfare, without compromising the sustainable development of future generations, should be among the major driving forces fostering new technological developments. For this reason one of the main cornerstones in the evaluation of new chemical processes is the socioeconomic analysis, which encompasses a cost/benefit study based on the technical performance of the process and its broader effects in relation to society and market economy. Within the energy industry, socio-economic analysis acquires even more relevance, since this sector is facing paramount challenges worldwide, because of progressively increasing environmental concerns and the need for securing stable and sustainable energy resources in the long term.

The socio-economic analysis will endeavour to make an assessment of the benefits and drawbacks of methane decarbonisation in comparison with existing hydrogen production processes and will be complemented with a life cycle assessment (LCA) analysis to evaluate its environmental impact. The results of the LCA are also envisioned to be used as feedback to the design phase of the process definition to optimise the process from an environmental point of view; this could affect the material choice for the reactor and technological options for auxiliary tasks. The socio-economic analysis is expected to show some aspects related to the sustainability of the process as a whole.

\section{Results and discussion}

\section{Technical feasibility}

Preliminary experiments were conducted using stainless steel reactors in order to verify the liquid metal bubble column reactor concept [21]. Regarding material compatibility, corrosion (Fig. 6) was a very important issue when metallic materials are used for the construction of the reactor. In the case of tin, the preferred material from its chemical and fluid-mechanics behaviour [16] [17] [19] [21], the corrosion rates for steels at the temperature of the process are very high, of the order of $30 \mu \mathrm{m} / \mathrm{h}$ at $700{ }^{\circ} \mathrm{C}$ [22]. More sophisticated materials such as tungsten and molybdenum have been identified as structural materials, as well as quartz or alumina. 


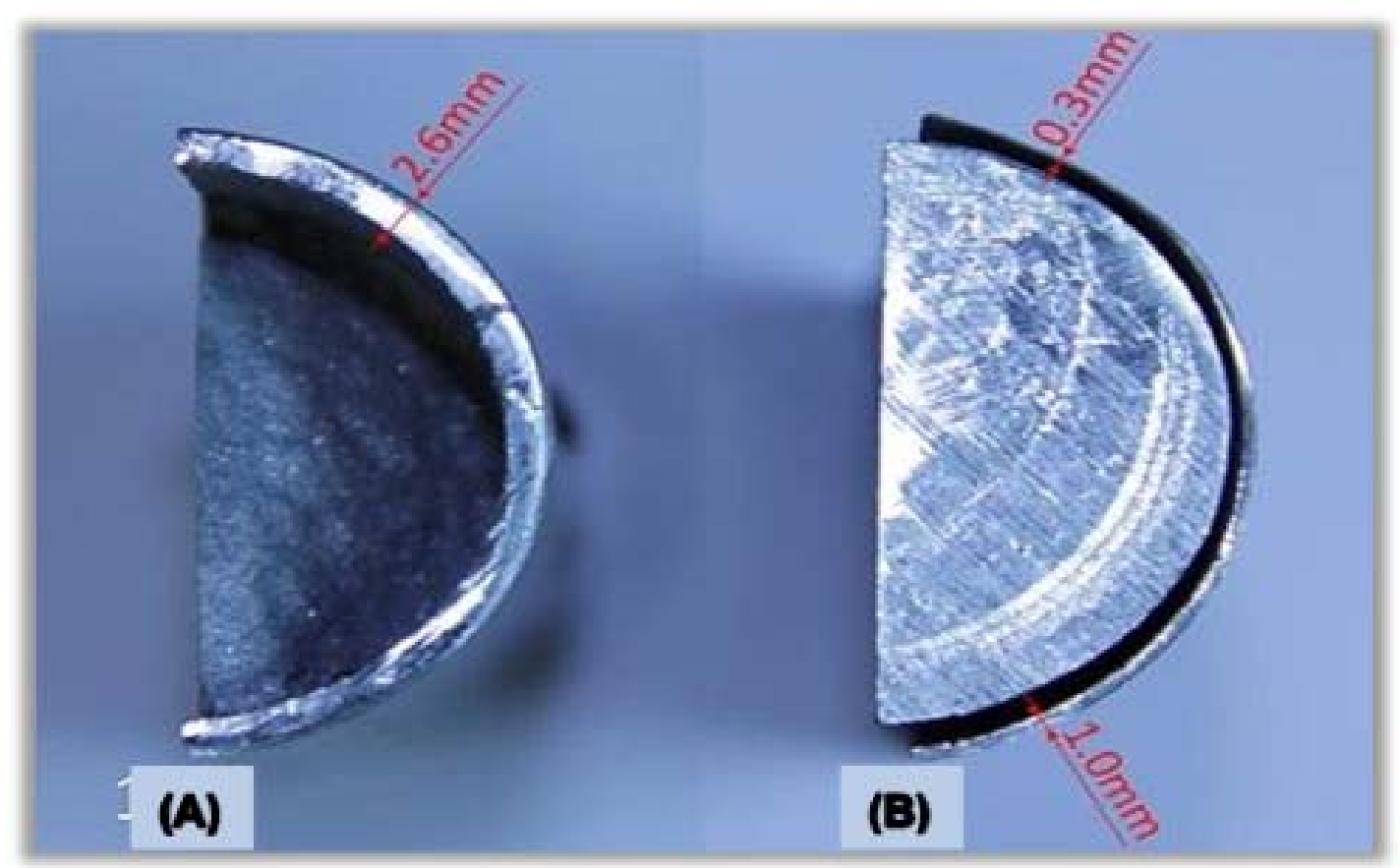

Fig. 6 - Cross-sections of the stainless steel reactor tube at different heights: (A) from a lowtemperature lower section and (B) from a high-temperature upper section showing reduced wall thickness due to corrosion by liquid tin.

Based on the experience from the preliminary experimental campaigns [21], a liquid metalpacked bed reactor was designed and fabricated using a combination of quartz glass and stainless steel and operated at temperatures between 820 and $1000{ }^{\circ} \mathrm{C}$ in a dedicated facility set up at KIT (Fig. 7); a detailed description of the recent reactor design and the resulting experimental setup is available in Ref. [23]. It could be seen from Fig. 8(A) that the hydrogen mole fraction in the exit gas increased with the decrease in the inlet methane flow rate. The decrease in the inlet methane flow rate corresponds directly to an increase in the gas residence time which in turn leads to a higher methane to hydrogen conversion. A maximum hydrogen mole fraction in the product gas of around 45 vol.- $\%$ was measured at $1000{ }^{\circ} \mathrm{C}$ and $50 \mathrm{ml} / \mathrm{min}$ inlet methane flow rate (Fig. 8(A)). The inlet methane flow rates that we have used, 50$200 \mathrm{ml} / \mathrm{min}$, are an order of magnitude higher than previous works in the field [17]. The hydrogen flow rates have been estimated from the measured hydrogen mole fractions and presented in Fig. 8(B). It is evident that higher hydrogen flow rates are produced when the inlet methane flow rates are higher, especially at higher temperatures. No significant amounts of intermediate products such as ethane or ethylene have been detected. Nevertheless, scope for further improvement in the reactor design still exists and extended experimental effort in this direction is in progress. Regarding the carbon, it was found within the experimental apparatus in the form of fine powder mainly in the free space at the top of the liquid metal surface without blocking the reactor during its operation. This carbon was completely separated from the liquid metal and the reactor wall (Fig. 9). 
Nov. 2016

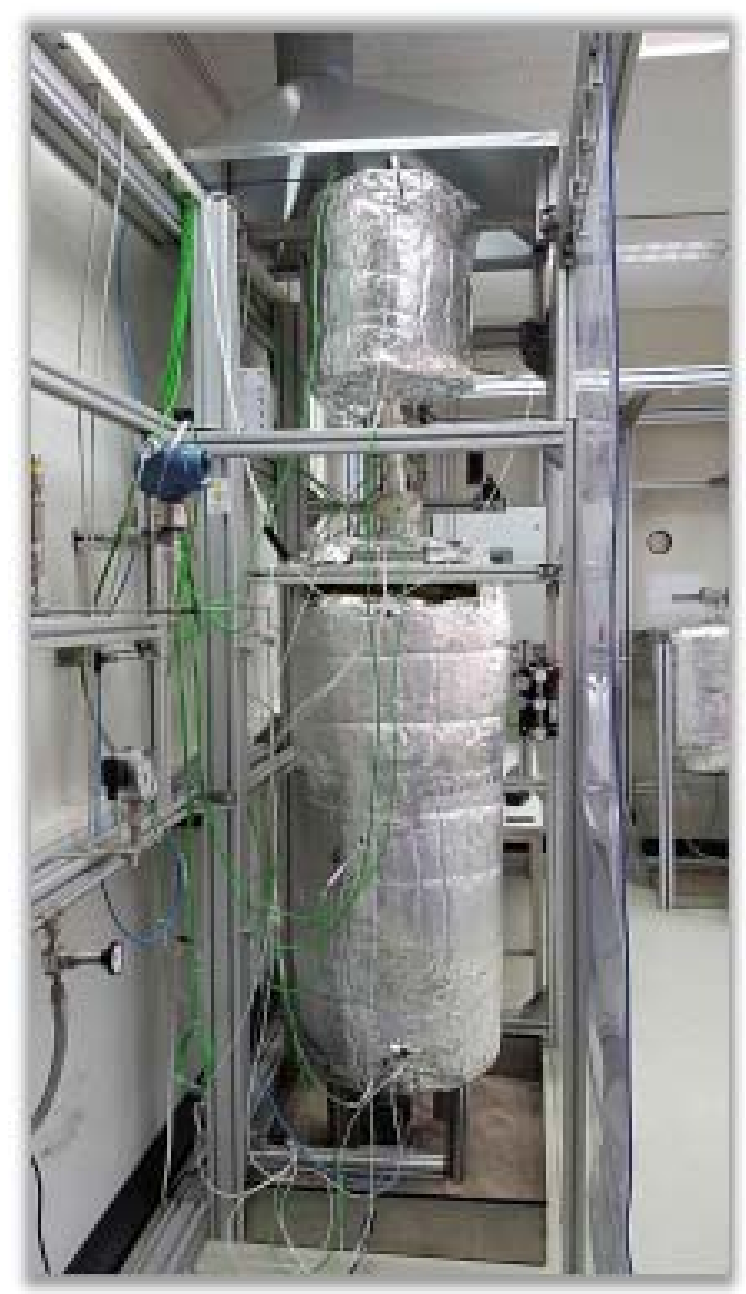

Fig. 7 - Photograph of the methane cracking experimental facility at KIT showing the insulated liquid metal reactor in the bottom. 


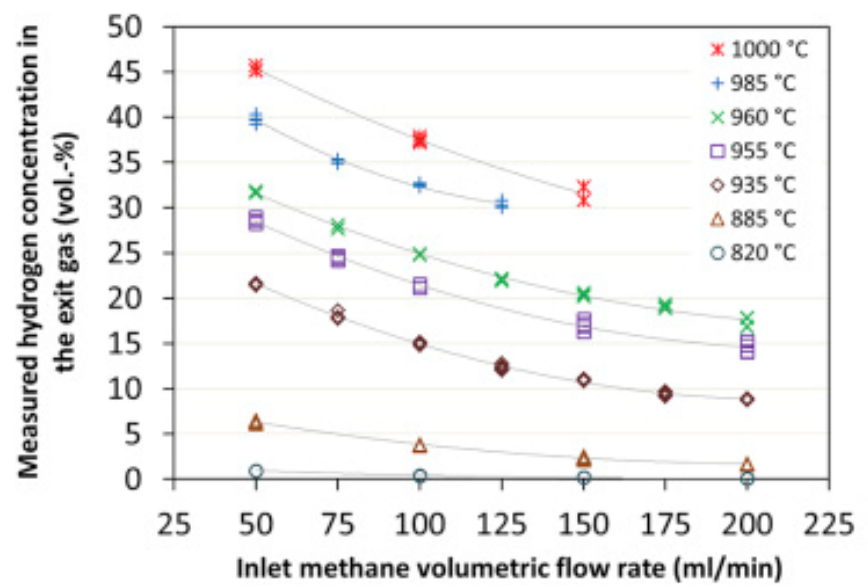

(A)

$\times 1000^{\circ} \mathrm{C}+985^{\circ} \mathrm{C} \times 960^{\circ} \mathrm{C} \quad \square 955^{\circ} \mathrm{C} \quad 0935^{\circ} \mathrm{C} \quad \triangle 885^{\circ} \mathrm{C} \quad 0820^{\circ} \mathrm{C}$

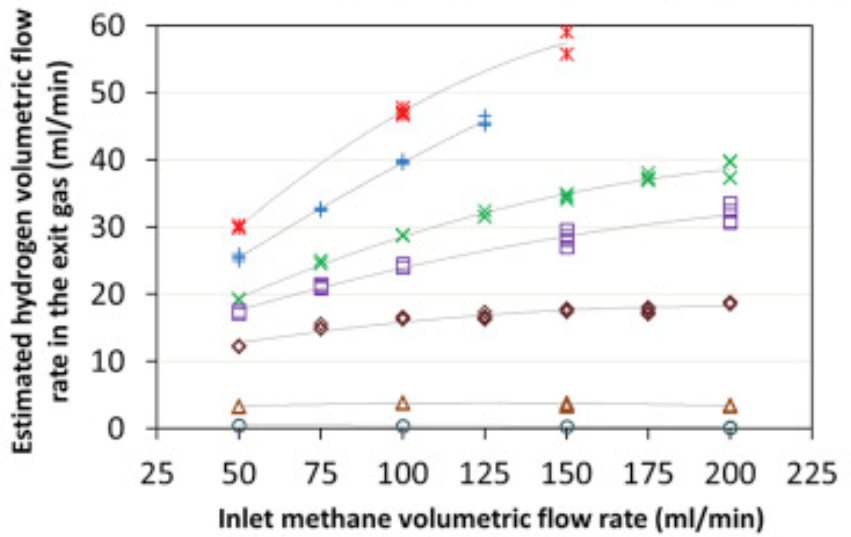

(B)

Fig. 8 - Hydrogen production as a function of inlet methane flow rate and temperature in our experimental reactor: (A) measured hydrogen mole fraction in the product gas and (B) estimated hydrogen flow rates.

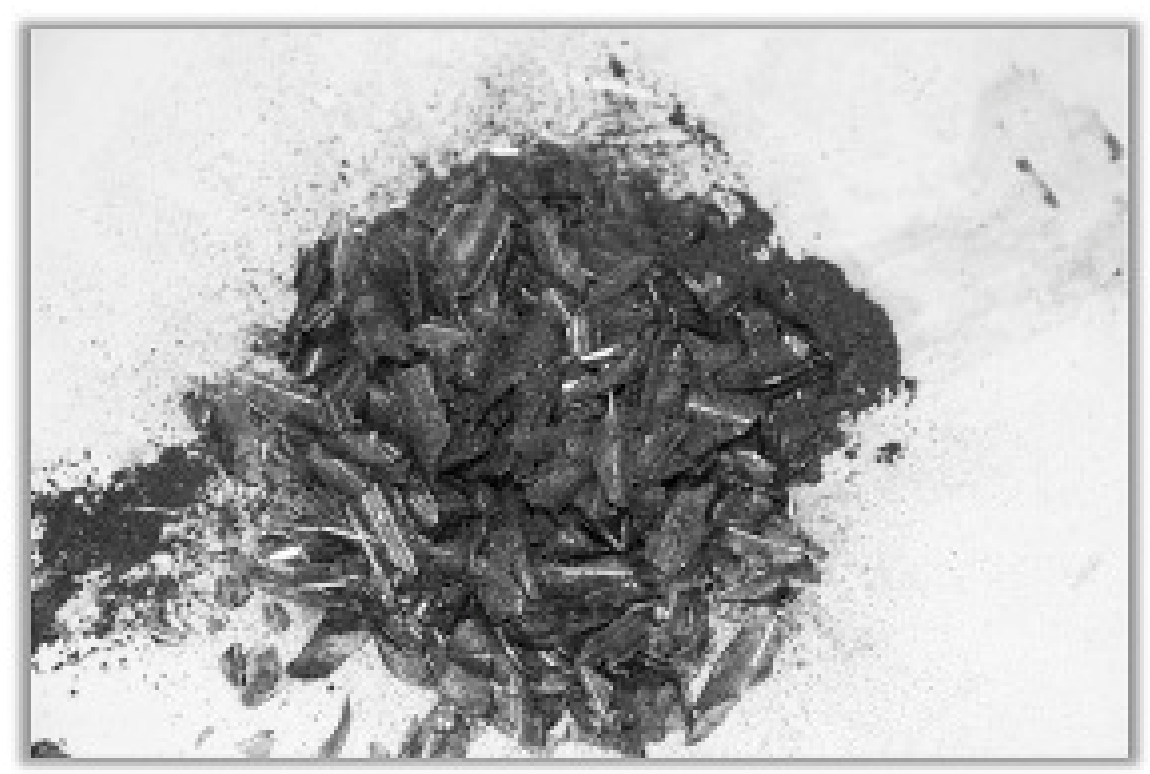

Fig. 9 - Carbon powder accumulated on top of the surface of the liquid metal along with quartz glass pieces that formed the packed bed. 


\section{Process scheme}

The results of the experimental work have shed some light about the characteristics of the process that should be implemented for an industrial development of this technology. A basic process scheme (Fig. 10) has been formed from the following functional units:

- Feed preparation: The raw natural gas may need a preparation unit to increase the methane content and to remove impurities.

- Reactor: The liquid metal bubble column reactor is envisaged to be made of quartz glass and operated at temperatures above $1000{ }^{\circ} \mathrm{C}$.

- Heating: The heating to provide the energy for the reactor is based on two options for an industrial implementation: a hydrogen burner or a methane burner. Additionally, the integration with solar technology is envisaged for further stages, but that will imply higher capital costs.

- Carbon removal from the reactor: The carbon obtained from our experiments has been characterized [23] and work is in progress for the conceptual design of a carbon removal process.

- Carbon separation from the gas stream: A filter is proposed to remove small quantities of carbon particles from the gas stream.

- Hydrogen separation from the process stream: There are two main options under consideration: pressure swing absorption (PSA), a mature technique applied for $\mathrm{CO}_{2}$ sequestration, and metallic membranes. Unreacted methane after separation from the process stream will be recycled back to the reactor.

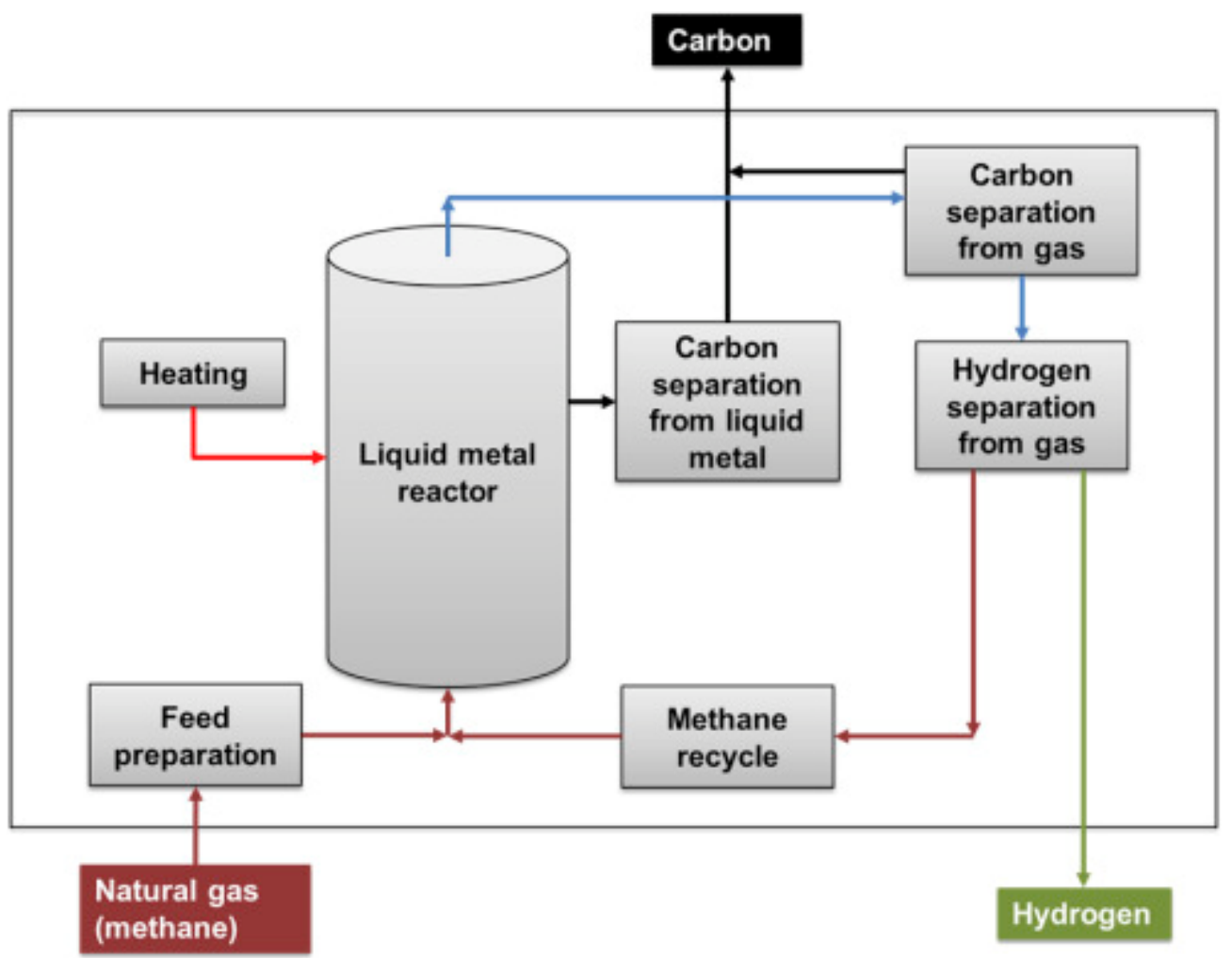

Fig. 10 - Basic methane decarbonisation process definition. 


\section{Socio-economic analysis}

The comparison of methane pyrolysis with other developed methods for hydrogen production from fossil-fuels is displayed in Table 1. From this theoretical comparison, that should be checked in a demo facility, the production of $100 \mathrm{Mtoe}$ (toe $=$ ton of oil equivalent $)$ of hydrogen will produce 103.8 Mton of carbon with methane cracking, avoiding the production of 255.18 Mton of $\mathrm{CO}_{2}$ with Steam Methane Reforming, or 626.85 Mton $\mathrm{CO}_{2}$ in comparison with coal gasification. The volume of $\mathrm{CO}_{2}$ to be sequestrated and managed in supercritical state will be 10 times larger than the volume of carbon produced for the same hydrogen energy generation, substituting the management of carbon dioxide with solid carbon, which may have additional applicability as well. The application of methane decarbonisation can be especially convenient in industrial sectors, as in the case of ammonia production, in which huge amounts of hydrogen are required.

Table 1 - Comparison of hydrogen production technologies from fossil-fuels [16] [1].

\begin{tabular}{llll}
\hline Process & Methane steam reforming & Coal gasification & Methane pyrolysis \\
\hline Reaction & $\mathrm{CH}_{4}+2 \mathrm{H}_{2} \mathrm{O}=\mathrm{CO}_{2}+4 \mathrm{H}_{2}$ & $\mathrm{C}+2 \mathrm{H}_{2} \mathrm{O}=\mathrm{CO}_{2}+2 \mathrm{H}_{2}$ & $\mathrm{CH}_{4}=\mathrm{C}+2 \mathrm{H}_{2}$ \\
Heat of reaction $\left(\mathrm{kJ} / \mathrm{mol}-\mathrm{H}_{2}\right)$ & 63.25 & 89.08 & 37.43 \\
Energy efficiency in transformation (\%) & 74 & 60 & 55 \\
Energy efficiency with CCS (\%) & 54 & 43 & 55 \\
$\mathrm{CO}_{2}$ emission (mol-CO $\left./ \mathrm{mol}-\mathrm{H}_{2}\right)$ & 0.34 & 0.83 & 0.05 \\
Carbon production $\left(\mathrm{mol}-\mathrm{C} / \mathrm{mol}_{2}\right)$ & 0 & 0 & 0.5 \\
\hline
\end{tabular}

From the preliminary economic analysis, the $\mathrm{H}_{2}$ production cost that can be expected from industrial methane cracking could be of the order of $1.5 \$ / \mathrm{kg}$, but this would be confirmed by the end of the project. In a previous analysis of methane decarbonisation [2], a $\mathrm{H}_{2}$ cost of around $3.0 \$ / \mathrm{kg}$ for solar methane pyrolysis was reported; the higher cost was mainly due to the solar field, which represents a significant capital cost of the facility.

\section{Conclusions}

The up-to-date status of the collaborative project between IASS and KIT aimed at the development of a technology to produce $\mathrm{CO}_{2}$-free hydrogen from methane based on liquid metal technology in a bubble column reactor has been described. Some advances regarding the technical feasibility of the liquid metal reactor concept based on the experimental work, progressing in parallel to the design of the process engineering for its implementation, have been reported. Until now, no critical technological show-stoppers have been found. Experimental measurements have shown that significant quantities of hydrogen can be produced continuously using the liquid metal bubble column reactor. Further work focused on improving the reactor design and optimising the operating conditions to increase the hydrogen production rate is in progress. The scale-up of the reactor from the experiment to an industrial size will be done to assess the technical viability of the concept. The socio-economic analysis predicts a reasonable hydrogen production cost that should be confirmed with additional comprehensive economic analysis.

\section{Acknowledgement}

This study was financially supported by the Institute for Advanced Sustainability Studies (IASS) in a collaboration agreement with the Karlsruhe Institute of Technology (KIT). 


\section{References}

[1] A. Abánades, C. Rubbia, D. Salmieri. Thermal cracking of methane into hydrogen for a $\mathrm{CO}_{2}$-free utilization of natural gas. Int J Hydrogen Energy, 38 (20) (2013), pp. 8491-8496

[2] N.Z. Muradov, T.N. Veziroğlu. "Green" path from fossil-based to hydrogen economy: an overview of carbon-neutral technologies. Int J Hydrogen Energy, 33 (23) (2008), pp. 6804-6839

[3] A. Abánades, C. Rubbia, D. Salmieri. Technological challenges for industrial development of hydrogen production based on methane cracking. Energy, 46 (1) (2012), pp. 359-363

[4] C. Guéret, M. Daroux, F. Billaud. Methane pyrolysis: thermodynamics. Chem Eng Sci, 52 (5) (1997), pp. $815-827$

[5] F. Billaud, C. Gueret, J. Weill. Thermal decomposition of pure methane at $1263 \mathrm{~K}$. Experiments and mechanistic modelling. Thermochim Acta, 211 (1992), pp. 303-322

[6] D.G. Goodwin, H.K. Moffat, R.L. Speth. Cantera: an object-oriented software toolkit for chemical kinetics, thermodynamics, and transport processes. (2014) vol. Software Toolkit, no. Version 2.1.2 http://www.cantera.org

[7] A.M. Amin, E. Croiset, W. Epling. Review of methane catalytic cracking for hydrogen production. Int J Hydrogen Energy, 36 (4) (2011), pp. 2904-2935

[8] H.F. Abbas, W. Wan Daud. Hydrogen production by methane decomposition: a review. Int J Hydrogen Energy, 35 (3) (2010), pp. 1160-1190

[9] D. Serrano, J. Botas, R. Guil-Lopez. $\mathrm{H}_{2}$ production from methane pyrolysis over commercial carbon catalysts: kinetic and deactivation study. Int J Hydrogen Energy, 34 (10) (2009), pp. 4488-4494

[10] U. Ashik, W. Wan Daud, H.F. Abbas. Production of greenhouse gas free hydrogen by thermocatalytic decomposition of methane - a review. Renew Sustain Energy Rev, 44 (2015), pp. 221-256

[11] J. B. Pohlenz and N. H. Scott, Method for hydrogen production by catalytic decomposition of a gaseous hydrocarbon stream. USA Patent US3284161 A, 8 November 1966.

[12] M.S. Rahman, E. Croiset, R.R. Hudgins. Catalytic decomposition of methane for hydrogen production. Top Catal, 37 (2) (2006), pp. 137-145

[13] V.R. Choudhary, S. Banerjee, A.M. Rajput. Continuous production of $\mathrm{H}_{2}$ at low temperature from methane decomposition over $\mathrm{Ni}$-containing catalyst followed by gasification by steam of the carbon on the catalyst in two parallel reactors operated in cyclic manner. J Catal, 198 (1) (2001), pp. 136-141

[14] A. Abánades, E. Ruiz, E. Ferruelo, F. Hernández, A. Cabanillas, J. Martínez-Val, et al. Experimental analysis of direct thermal methane cracking. Int J Hydrogen Energy, 36 (20) (2011), pp. 1287712886

[15] D. Tyrer, Production of hydrogen. USA Patent US1803221 A, 28 April 1931. 
[16] M. Steinberg. Fossil fuel decarbonization technology for mitigating global warming. Int J Hydrogen Energy, 24 (8) (1999), pp. 771-777

[17] M. Serban, M.A. Lewis, C.L. Marshall, R.D. Doctor. Hydrogen production by direct contact pyrolysis of natural gas. Energy Fuels, 17 (3) (2003), pp. 705-713

[18] P. Martynov, A. Gulevich, Y. Orlov, V. Gulevsky. Water and hydrogen in heavy liquid metal coolant technology. Prog Nucl Energy, 47 (1-4) (2005), pp. 604-615

[19] D. Paxman, S. Trottier, M. Nikoo, M. Secanell, G. Ordorica-Garcia. Initial experimental and theoretical investigation of solar molten media methane cracking for hydrogen production. Energy Procedia, 49 (2014), pp. 2027-2036

[20] I. Schultz, D.W. Agar. Decarbonisation of fossil energy via methane pyrolysis using two reactor concepts: fluid wall flow reactor and molten metal capillary reactor. Int J Hydrogen Energy, 40 (35) (2015), pp. 11422-11427

[21] M. Plevan, T. Geißler, A. Abánades, K. Mehravaran, R. Rathnam, C. Rubbia, et al. Thermal cracking of methane in a liquid metal bubble column reactor: experiments and kinetic analysis. Int J Hydrogen Energy, 40 (25) (2015), pp. 8020-8033

[22] H. Shimotake, J. Hesson. Static and dynamic corrosion by tin, bismuth and bismuth-sodium alloy up to $1000^{\circ} \mathrm{C}$. Trans Am Nucl Soc, 8 (1965), p. 3

[23] T. Geißler, M. Plevan, A. Abánades, A. Heinzel, K. Mehravaran, R. Rathnam, et al. Experimental investigation and thermo-chemical modeling of methane pyrolysis in a liquid metal bubble column reactor with a packed bed. Int J Hydrogen Energy, 40 (41) (2015), pp. 14134-14146 